\title{
Chapter 15 \\ Possible Impact of Pelletised Crop \\ Residues Use as a Fuel for Cooking \\ in Niger
}

\author{
Stefano Bechis
}

\begin{abstract}
One of the main causes of deforestation in Africa is the cutting of trees for cooking purposes. Even though gas and other fuels are available, in theory, their diffusion is slower than the increase of the population that continues to use wood as a fuel. The trends for the near future show that, in many areas, the forests will disappear and expose the soil to desertification. An intermediate solution to address the deforestation problem can be the use of other biomass sources, different from the traditional wood sticks, for cooking. In this paper, a system that uses agricultural residues and tree prunings, instead of wood, as a fuel, is introduced. The work done consisted in setting up a pellet making facility, and a gasifier stove. The results obtained by the pellet fuelled stove, show that its efficiency is higher than that of the improved cook stoves that use wood, and that, in addition, the stove does not produce smoke during normal cooking operation, making its use safer for the operators and other persons close to the fire.
\end{abstract}

Keywords Woodfuel • Deforestation · Gasification • Residues biomass

\subsection{Introduction}

During the last three decades, worldwide, the total number of people using biomass for cooking, around 2.7 billion, remained the same. The percentage of the world population that uses biomass for cooking purpose has been decreasing, and this might be regarded as a fairly positive datum, but this reduction is only the result of the same number of people relying on firewood, divided by the rising total number of inhabitants on planet Earth (Fig. 15.1). As a matter of fact, the expected switch to fuels other than wood, in rural areas of Developing Countries, is still not happening, on a global scale. At continental scale, it can be noted that in Africa there is a rising number of people relying on biomass (Fig. 15.2), while in the Western Pacific

\footnotetext{
S. Bechis $(\bowtie)$

DIST, Politecnico and University of Turin, Viale Mattioli 39, 10125 Turin, Italy

e-mail: stefano.bechis@unito.it 


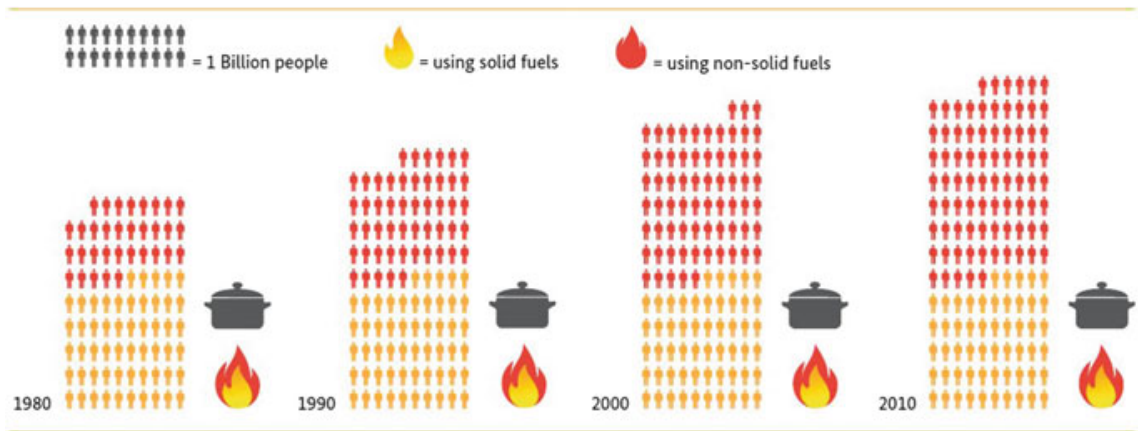

Fig. 15.1 Number of people using solid and non-solid fuels (Roth 2014 elaborated from Bonjour et al. 2013)

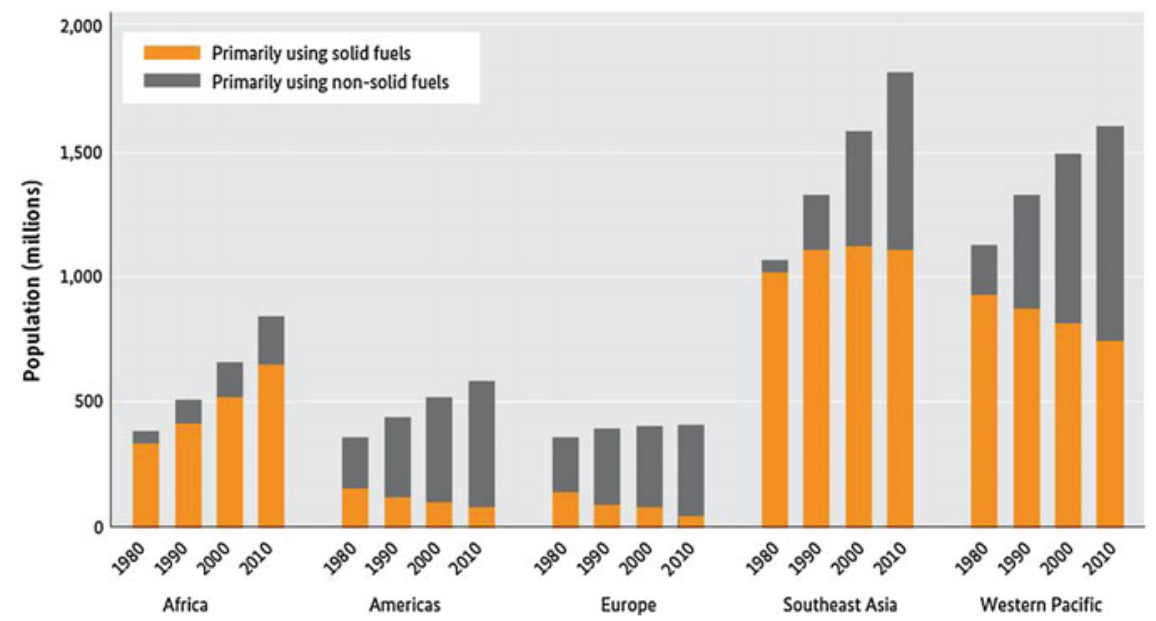

Fig. 15.2 Trend in the use of solid and non-solid fuels divided by geographical area (Roth 2014)

states, as well as in Europe and South America, the absolute number of people using biomass as a fuel is declining.

The strong increasing number of people using wood fuel in Africa, represents a serious sustainability problem over this issue in that specific continent.

The present deforestation process observed in Africa derives, in some sense, from decades of abundance of firewood. It has been reported (Ozer 2004) that before the great droughts of late 1960s, no shortage of firewood had been recorded. The supply of wood fuel exceeded the demand, and it was regarded as an infinite resource. For this reason, no measures to save firewood, using it in an efficient way, were studied and adopted. The firewood supply was limited to the collection of dead wood, even in small towns. Since no alive trees were cut for this purpose, the regeneration of the forest was assured. 


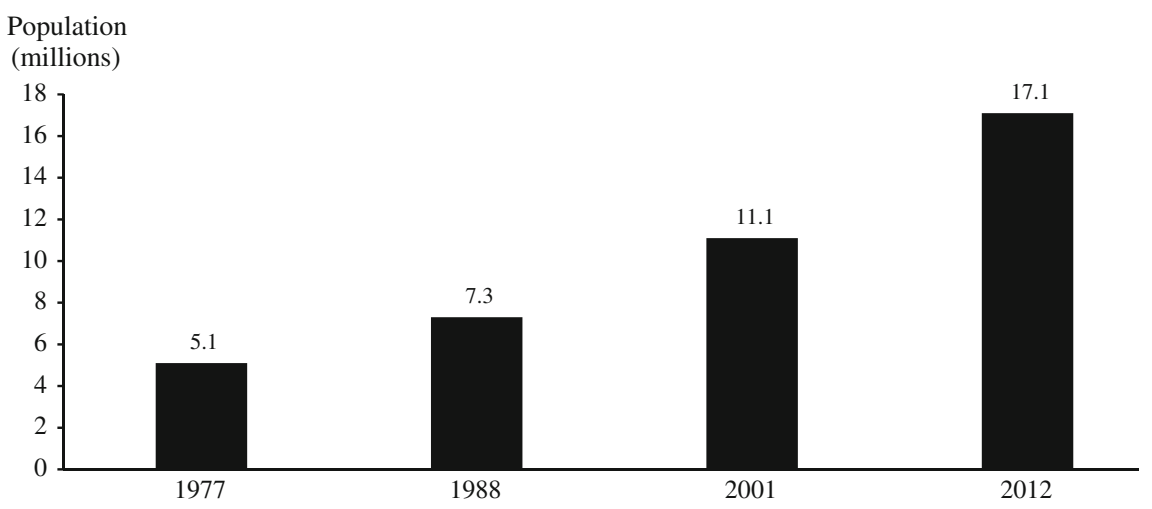

Fig. 15.3 Total population in Niger according to censuses from 1977 to 2012

The main driver in the increasing wood fuel consumption is the population increase in the countries that have the higher percentages of population using biomass as a source of energy. In Niger, where $96.4 \%$ of families use biomass for cooking purposes ( $\mathrm{RdN} 2014)$, the yearly population growth rate is the highest in the world, $3.9 \%$ in 2014. Niger population increased from around 5 million in 1977 to about 11 million in 2001, and to more than 17 million in 2012 (Gouro et al. 2014; RdN 2014) (Fig. 15.3).

Last estimations (http://countrymeter.info/en/Niger) indicate that population in Niger already exceeds 20 million in 2016. From the 1977 census, to the year 2016, the population quadrupled, in only 39 years.

It has to be pointed out that the rural population continues to grow, at least at the same rate as the urban population. Under this aspect, there is not, in Niger, a general migration towards cities, but a proportional growth of the population both in towns and in rural areas (Tarchiani and Tiepolo 2016).

In this same country, starting from 1990, more than the half of the natural forest has gone lost, and a recent survey (FAO 2015) indicates in less than 800,000 ha the remaining natural forest area (Fig. 15.4). Similar deforestation patterns are observed in several other African countries. Deforestation changes local climate, and is one of the main contributor to global warming (Watson et al. 2000).

To address the deforestation problem, the use of forest resources as wood fuel for cooking must be considered, together with the other causes.

The traditional three stone fire is still widespread in the whole country, and with an overall efficiency around only $15 \%$, it requires for a remarkable quantity of wood (Fig. 15.5). The reason why it is so popular, is that it is simply set up arranging three stones or bricks on the ground, with some wood pieces in the middle.

A number of improved cook stoves has been set up during the last decades, to improve the efficiency of cooking with wood. Unfortunately, those stoves are still not used in a diffuse way, and they still rely on wood sticks to work. To mark a considerable change from the present situation, a change of fuel is needed. 


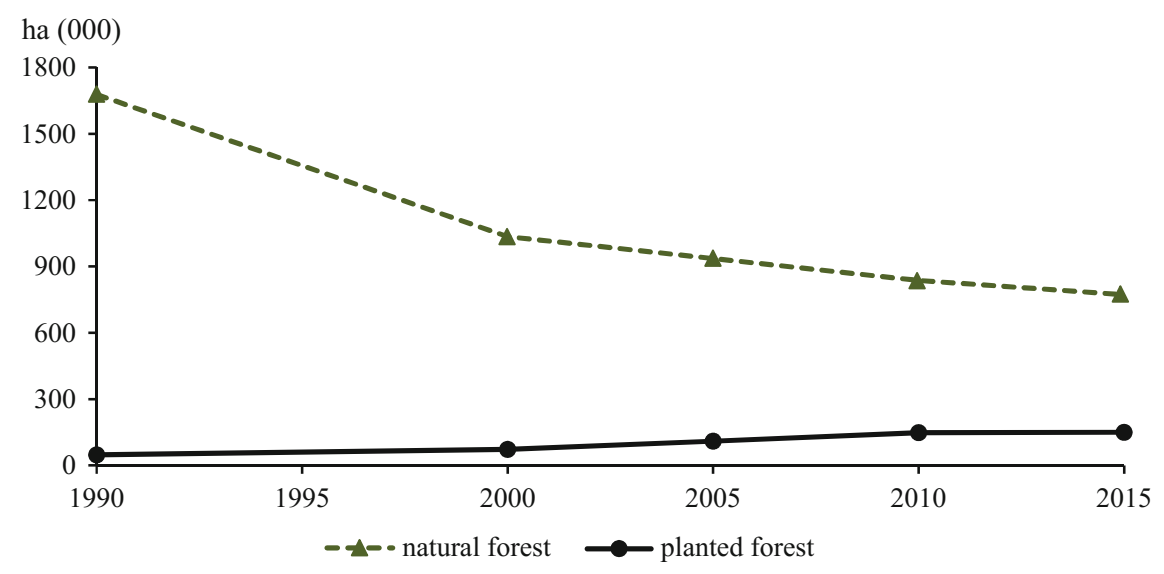

Fig. 15.4 Trends of forest land availability in Niger between 1990 and 2015

Fig. 15.5 A three stone fire made with bricks

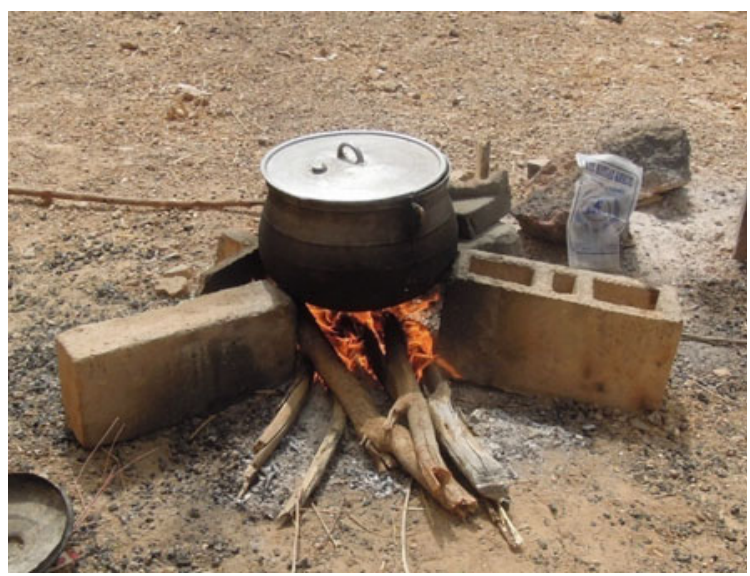

Looking into the biomass produced in Niger each year, besides wood, there is a considerable quantity of unused agricultural residues. Those residues can be used as a source of heat for cooking, if appropriately prepared to be burned, or gasified.

Taking into consideration the agricultural production (FAO 2013), it is possible to estimate the quantity of agricultural residues applying the RPR-Residue to Product Ratio conversion index (Lal 2005; Ryan and Openshaw 1991), that indicates the residual biomass produced for each ton of crop production (Table 15.1). A quantity up to $30 \%$ of crop residues removal is considered safe under the point of view of possible soil loss (Lindstrom 1986). Some differences in crop residues removal have been observed, with stress on variables like the kind of tillage, soil moisture, and temperature. For these reasons, residue removal effect is site-specific, and cannot be generalized. 
Table 15.1 Niger main agricultural crops production and estimate of residual mass

\begin{tabular}{l|l|l|l}
\hline Crop & Production mass T 000 & RPR & Residue mass T 000 \\
\hline Millet & 2995 & $1.51^{\mathrm{a}}$ & 4544 \\
\hline Cow peas, dry & 1300 & $2.90^{\mathrm{b}}$ & 3770 \\
\hline Sorghum & 1287 & $1.50^{\mathrm{a}}$ & 1931 \\
\hline Groundnuts, with shell & 280 & $1.00^{\mathrm{a}}$ & 280 \\
\hline Sugar cane & 190 & $0.25^{\mathrm{a}}$ & 48 \\
\hline Cassava & 150 & $0.20^{\mathrm{b}}$ & 30 \\
\hline Sweet potatoes & 97 & $0.25^{\mathrm{a}}$ & 24 \\
\hline Potatoes & 88 & $0.25^{\mathrm{a}}$ & 22 \\
\hline Rice, paddy & 40 & $1.50^{\mathrm{a}}$ & 60 \\
\hline Oilseeds & 35 & $1.37^{\mathrm{a}}$ & 48 \\
\hline Total & 6462 & & 10,756 \\
\hline
\end{tabular}

${ }^{\mathrm{a}} \mathrm{Lal}(2005)$

${ }^{\mathrm{b}}$ Ryan and Openshaw (1991)

\subsubsection{Present Use of Agricultural Residues in Niger}

The agricultural residues have different uses.

- some residues are used to feed animals. In this case, livestock is left free to access the fields where the residues are, and the animals directly feed on the edible part of the residues.

- some residues are simply left on the ground, and they degrade under the action of environmental factors.

- some residues are burned directly in the fields, before seeding or transplanting a new crop, if their mass is seen as an obstacle to the agricultural operations.

- in some areas where wood fuel is particularly scarce, some kind of residues, as the biggest millet stalks, are already used by the local population to be burned for cooking purposes.

The use to feed animals is particularly important in Niger, as it is reported that already $37.8 \%$ of cereals residues, and $85.7 \%$ of legumes residues, are already used, for this purpose (Karimou and Atikou 1998).

When using agricultural residues, a special attention has to be given to the preservation of soil quality, to prevent an excessive removal of crop residues to depress physical and nutritional characteristics of the land (Lal 2005). Where the removal of residues is already high, further removal should be avoided, in order to protect the soil characteristics.

Other residues that can be used as a raw material to produce pellets are tree pruning and dry leaves. Those residues are abundant in urban areas, and, after they are gathered in piles, they are often set in fire directly in the streets, in order to reduce their mass. 


\subsection{Methodology}

The present work intends to contribute to reduce the use of wood fuel for cooking purposes, in order to reverse the tendency in deforestation. To achieve the objective of the work, two different tasks have been accomplished:

1. setting up of a gasification stove specifically designed for the Nigerian traditional cooking exigencies

2. start and optimization of a pellet production chain from agricultural residues and wooden pruning

These two tasks have been carried out in the framework of a EU funded Energy facility project, Renewable energies in the Agadez et Tillabéri regions, under the direction of the Italian NGO Terresolidali (Bechis et al. 2014). The setting up of the gasification stove was carried out starting from an existing model (Brace Research Institute 1999). This P-1 gasification stove (Figs. 15.6 and 15.7) has been adapted to the pots largely used in Niger, and to the requested cooking conditions of the average family.

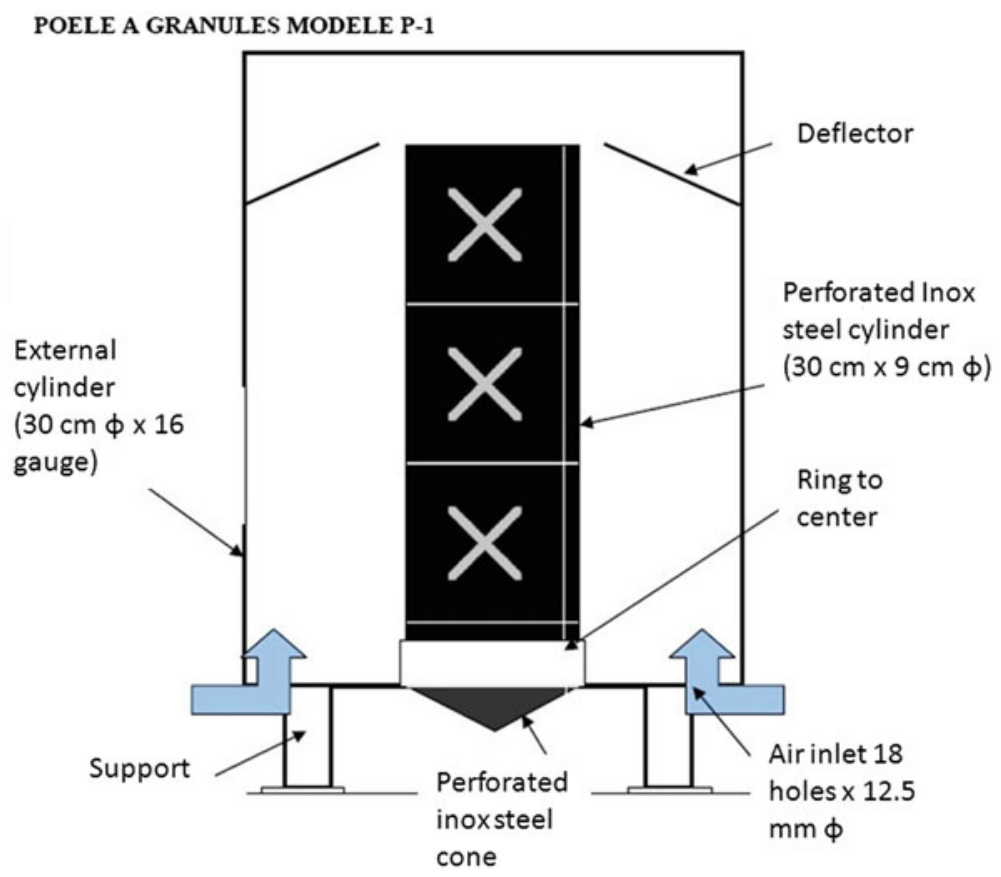

Fig. 15.6 The project of the P-1 gasification stove produced by the Brace Research Institute of Montréal, Canada 

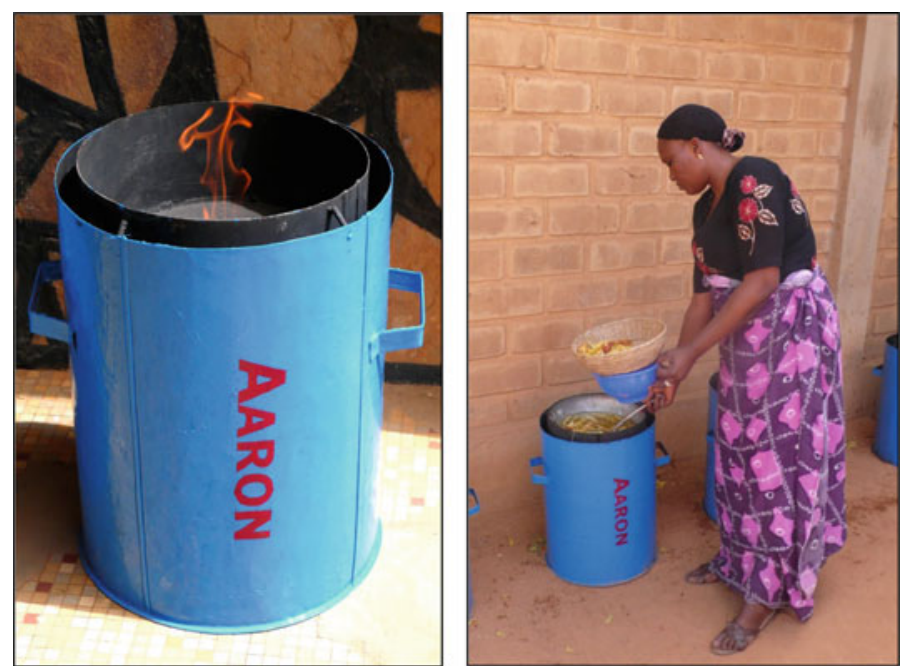

Fig. 15.7 The gasification stove developed

The project requirements for the stove can be summarized as:

1. perform the gasification of fuel

2. reach a high overall efficiency

3. be able to cook a complete meal for the average Niger family ( 7 persons)

4. be stable, to allow stirring

5. be safe for users and children

6. be economic.

The gasification process is necessary to obtain better efficiencies, and a more complete combustion of the biomass used as a fuel.

The gasification process assures less smoke development, and consequently less health risks for the operator. To achieve a stable and steady gasification process, it was necessary to use the feedstock under the form of pellets. High efficiency in thermal conversion allows to perform the cooking of meals with the smallest possible quantity of fuel. As a consequence, high efficiency directly involves fuel savings, with positive effects on economy and sustainability.

To find the right proportions among the different parts of the stove, a first set of around 50 tests was carried out, modifying one parameter at a time. These first tests were performed in Italy, using commercial wooden pellets as a fuel, and $3 \mathrm{dm}^{3}$ of water as the heat receiver to assess the heat transfer.

After this first provisional set up, a series of tests were performed in Niger, including some tests where real cooking was performed, to collect the impressions and the suggestions of the potential users on the stove under development. The feedbacks of the users were particularly useful to assess the stove dimensions and stability, as well as the power and lasting of the flame for each fuel charge. 
The involvement of users in the early stages of development of the stove, was expressly done in order to take the users exigencies into account from the beginning, to develop a stove with the most suitable, or user friendly, design.

Besides the exigencies of the users, specific attention was paid to the practical building of the stove, in order to allow the local craftsmen to easily build it. Under this point of view, the choice was to make the production of the stove as simple as possible, with dimensions of the stove taking into account the dimensions of the iron sheets available on the Niger market, in order to produce the parts with fewer hours of work, and fewer material scraps.

In parallel with the development of the stove, tests were performed to produce pellets with agricultural residues collected in Niger.

The setting up of the pellet making process passed through a sequence of actions. First of all millet stalks were sent from Niger to Europe to perform the first pellet making tests on small Diesel powered machines. Second, the machines were exported to Niger and were tested on other different raw materials in various proportions. Third, the pellets produced in Niger were analysed at the University of Turin, to assess their physical characteristics. Finally, the produced pellets were used in the Aaron stove to assess their performance and in cooking tests (Fig. 15.8).

After the first experimental phase, and the construction of 350 stoves, a larger facility for the production of pellets, powered by electricity, has been established in the city of Niamey. Tests were also carried out on pellet making for fodder production. The advantages in pelletizing hay and the most edible residues are in a
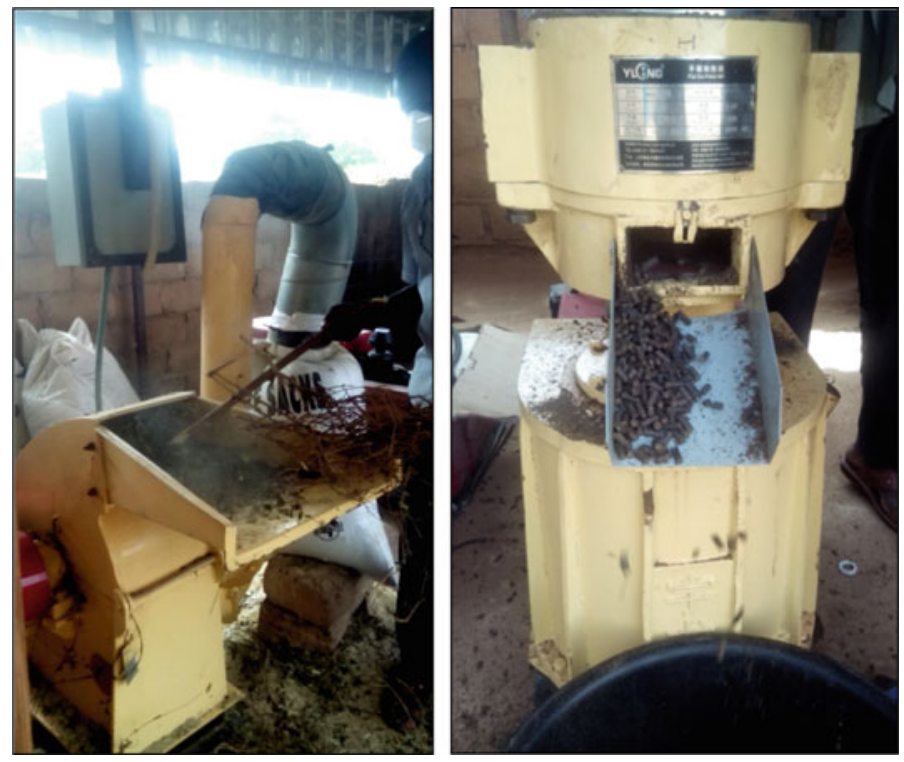

Fig. 15.8 The machines in the pellet making facility. The electric mill (left) and the pellet machine (right) 
higher product density and a better preservation of the nutritive value. The Aaron stove has been officially tested by the independent body CNES, the National Solar Energy Centre of Niger, and its results compared with those of other stoves (Boubacar 2013). To assess the economic sustainability of the entire pellets cycle, an economic analysis has been carried out by two researchers of the University of Zinder. The cost of pellets has been compared with the reference price for wood fuel in urban areas.

The analysis was completed by technical and economic observations on the feedstock supply chain for pellet making, with the aim to identify possible modifications, that would reduce the cost of the pellet making activity.

\subsection{Results and Discussion}

The proposed technology proved to be adapted to the local technical level. Craftsmen in Niamey and Agadez could build the stove, with the use of the tools normally available in the average Niger workshop, and a welder. After an investigation it was possible to identify a workshop where to perform the maintenance of the pellet making machines, working on the parts subject to wearing, and even manufacture some of them, as dies and rollers. The people trained in the use of the Aaron stove, quickly learned how to use it, and appreciated the possibility to stay comfortably close to the fire, breathing clean air, as the stove does not produce smoke.

The independent tests carried out by CNES certified that cooking with pellets in the Aaron stove saves $75 \%$ of biomass, in comparison with the consumption of the conventional, open 3-stone fire.

The cooking tests indicated that it is possible to cook a complete meal for the average Niger family, with 7 members, with about $1.4 \mathrm{~kg}$ of pellets $(0.20 \mathrm{~kg} / \mathrm{day}$ per person). With the traditional three-stone fire still largely used both in rural and urban areas, the quantity of wood fuel necessary to accomplish the same task is one bundle of wood sticks. A series of measures indicated that the average weight of a bundle is approximately $5.8 \mathrm{~kg}$. This fixes the quantity necessary per person in $0.83 \mathrm{~kg} /$ day.

Starting from these figures, taking into account the latest indications on Niger population, slightly over 20 million people in 2016 , and the percentage of the total population using biomass as a source for cooking, $96.4 \%$, the need for cooking with woodfuel in traditional fires, for the whole Niger population, can be estimated in 5.83 million t per year, while the same projection, in case of a general use of the system developed in this project, is of 1.4 million $t$ of pellets per year.

Under the economic point of view, the study carried out by at the University of Zinder focussed on the production cost of pellets, and on the possibility for the pellets to compete with the traditional wood sticks on the market (Middah et al. 2015). 
A comparison of the costs of cooking with wood sticks in the three stone fire and with pellets in the Aaron stove, needs to consider the cost per unit and the number of units necessary to perform the cooking of one meal. The cost of wood sticks varies widely, depending on the site, and on the season. In the capital Niamey, on average, this cost is around 230 FCFA per bundle ( 0.35 Euros/bundle). Divided by the weight of the bundle, the cost results approx. equal to 40 FCFA per $\mathrm{kg}(0.06$ Euro $/ \mathrm{kg})$. The cost of one $\mathrm{kg}$ of pellets is higher, around 100 FCFA $(0.15 \mathrm{Euro} / \mathrm{kg})$. Taking into account the quantity needed to cook one meal, $1.4 \mathrm{~kg}$ of pellets, they cost about 140 FCFA (0.21 Euro per meal) while to cook one meal with the three stone fire an entire bundle of wood sticks is needed. Then, even though the unit cost of pellets is higher, as a small mass of pellets is needed in comparison with wood sticks, to cook a meal, the use of pellets involves an economy of 90 FCFA (around 0.14 Euro) for the preparation of each meal. The costs described, are for the present production rate of pellets, in case of an increase in pellet production, an economy of scale is expected (Fig. 15.9). The two researchers suggested improvements for the organisation of the residues supply chain, with the use of a motorised cart, that would reduce the specific production cost.

The measures taken on pellets made with hay, indicated that the pelletized fodder had seven times higher density than the hay stored in the traditional way. A more dense fodder is easier to store and transport. This development of the project will be object of further investigation.

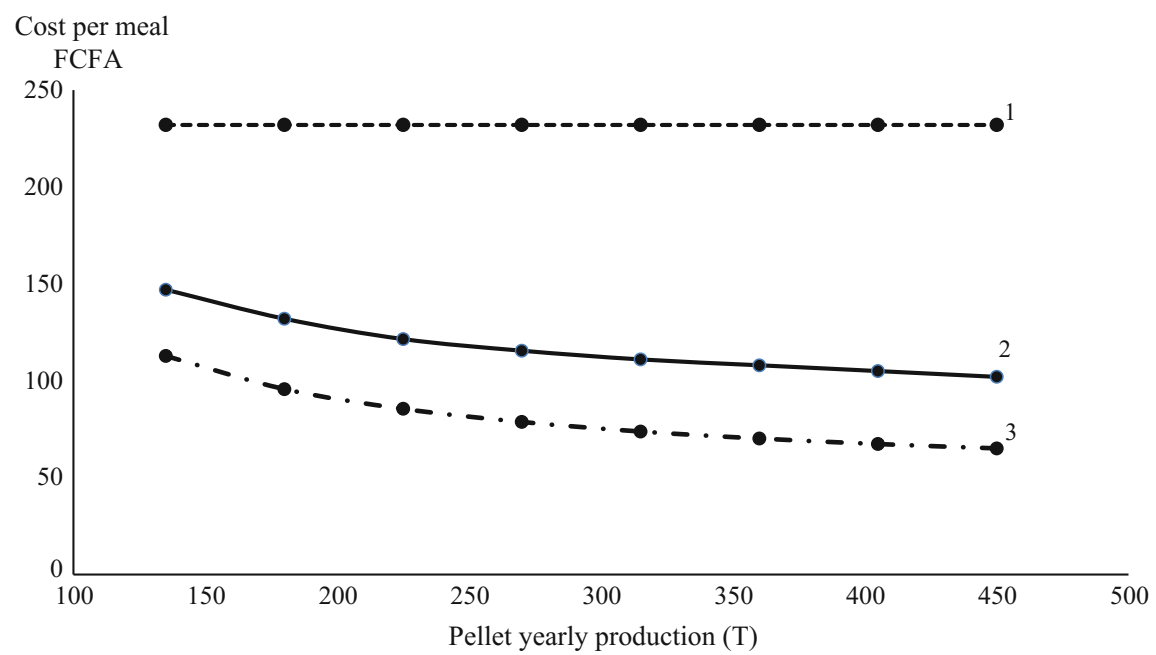

Fig. 15.9 The resulting price of pellet for increasing production quantities at the Niamey pellet production facility. 1 . the wood fuel reference price, 2 . the present price for pellets as a function of the yearly production at the plant, 3 . the calculated price after an enhancement of the feedstock delivery chain 


\subsection{Conclusions}

The achievements of the present work demonstrated that agricultural residues are suitable as a cook fuel in Niger. Their adoption on a large scale mainly depends on the organization of a supply chain of pelletized fuel to the consumers, and on public policies, as the cost of the gasification stove is important when compared to the revenue of the average rural Niger family.

Under the technical point of view, the system developed with pellet making and the gasification stove to use it, can potentially have a significant impact on forests conservation, if it is implemented on a large scale.

A second important aspect of this system is linked to the gasification process, that produces much less harmful smoke than direct burning of biomass. The Aaron stove and its gasification system is likely to have a positive impact on health issues linked to the use of firewood.

Attention has to be paid to the amount of crop residues removed from the fields. In areas where the removal of agricultural residues is already high, due to the use of agricultural residues as fodder for animals, further removal should be avoided, in order to protect the soil quality.

\section{References}

Bechis, S. et al. 2014. The Aaron stove, switching to agricultural residues to save firewood. ASABE and CSBE Annual International Meeting. Montréal.

Bonjour, S., et al. 2013. Solid fuel use for household cooking: country and regional estimates for 1980-2010. Environmental Health Perspectives 121 (7): 784-790. doi:10.1289/ehp.1205987.

Boubacar, S. 2013. Résultats des tests sur le foyer Aaron. Niamey: CNES, Centre National d'Energie Solaire.

Brace Research Institute. 1999. Conception de poêles multifonction à biomasse densifiée en granules pour usages domestiques et communautaires. Montréal: Faculty of Engineering, McGill University, Report No. I-378-P-267.

FAO. 2015. FAO Global forest resources assessment. http://www.fao.org/3/a-i4793e.pdf.

FAO. 2013. FAO statistical yearbook. http://www.fao.org/docrep/018/i3107e/i3107e00.htm.

Gouro, A.S., C. Ly, H. Makkar. 2014. Résidus agricoles et sous-produits agro-industriels en Afrique de l'ouest. État des lieux et perspectives pour l'élevage. Accra: Bureau régional pour l'Afrique de la FAO.

Karimou, M., and A. Atikou. 1998. Les systèmes agriculture-élevage au Niger. In The dry savannas of West and Central Africa, ed. G. Tarawali, and P. Hiernaux, 78-97. Ibadan: IITA.

Lal, R. 2005. World crop residues production and implications of its use as a biofuel. Environment International 32 (4): 575-584. doi:10.1016/j.envint.2004.09.005.

Lindstrom, M.J. 1986. Effects of residue harvesting on water runoff, soil erosion and nutrient loss. Agriculture, Ecosystems \& Environment 16 (2): 103-112. doi:10.1016/0167-8809(86)90097-6.

Middah, D., C. Harira. 2015. Production des pellets Ong Terre Solidali Niger. Institut Universitaire de Technologie, University of Zinder and PREDAS Programme Régional de promotion des energies domestiques et alternatives au Sahel, Burkina Faso.

Ozer, P. 2004. Bois de feu et déboisement au Sahel: mise au point. Sécheresse 15 (3): 243-251. 
RdN-République du Niger, Institut National de Statistique du Niger. 2014. Le Niger en chiffres. http://www.stat-niger.org/statistique/file/Affiches_Depliants/Nigerenchiffres2014def.pdf.

Roth, C. 2014. Micro gasification 2.0 cooking with gas from dry biomass. Eschborn: GIZ.

Ryan, P., K. Openshaw. 1991. Assessment of biomass energy resources: a discussion on it's needs and methodology. World Bank.

Soil Quality National Technology Development Team. 2006. Crop residue removal for biomass energy production: effects on soils and recommendations. Technical note No. 19. USDA United States Department of Agriculture-NRCS National Resources Conservation Service soils.usda.gov/sqi.

Tarchiani, V., and M. Tiepolo (eds.). 2016. Risque et adaptation climatique dans la Région Tillabéri, Niger. Pour renforcer les capacités d'analyse et d'évaluation. Paris: L'Harmattan.

Watson, R.T., et al. 2000. Land use, land-use change and forestry. Cambridge, UK: Cambridge University Press and IPCC.

Open Access This chapter is licensed under the terms of the Creative Commons Attribution 4.0 International License (http://creativecommons.org/licenses/by/4.0/), which permits use, sharing, adaptation, distribution and reproduction in any medium or format, as long as you give appropriate credit to the original author(s) and the source, provide a link to the Creative Commons license and indicate if changes were made.

The images or other third party material in this book are included in the book's Creative Commons license, unless indicated otherwise in a credit line to the material. If material is not included in the book's Creative Commons license and your intended use is not permitted by statutory regulation or exceeds the permitted use, you will need to obtain permission directly from the copyright holder.

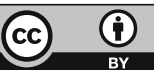

